Andrew Young School of Policy Studies Research Paper Series

Working Paper 08-01

January 2008

Department of Economics

Fiscal Research Center

\title{
Housing the Aging Baby Boomers: Implications for Local Policy
}

John W. Matthews

Georgia State University

Geoffrey K. Turnbull Georgia State University

This paper can be downloaded at:

http://aysps.gsu.edu/publications/2008/index.htm

The Social Science Research Network Electronic Paper Collection:

http://ssrn.com/abstract=1081305 


\title{
Housing the Aging Baby Boomers: Implications for Local Policy
}

\author{
John W. Matthews \\ Georgia State University \\ and \\ Geoffrey K. Turnbull* \\ Georgia State University
}

December, 2007

\begin{abstract}
Most elderly want to age in place. Yet, most elderly live in suburban and rural communities ill-suited to meet the changing aging-related demands. This paper discusses various issues communities need to address when balancing the demands of aging baby boomers against those of younger households. Accommodating changes in life stage needs requires revising building and zoning codes to permit mixed use and mixed density development incorporating greater varieties of housing units and easier accessibility. Developing support arrangements for naturally occurring retirement communities will become important for state and local governments. A significant number of aging adults will move to locales with natural and augmented civic amenities. Such migration is double-edged; features that attract "gray gold" also attract needy elderly. Finally, affordable housing will be an issue for a growing number of elderly, calling for targeted tax and financial assistance policies for lower income elderly homeowners.
\end{abstract}

Keywords: Aging population, elderly housing, aging policy

*Communications to: Geoffrey K. Turnbull, Department of Economics, Georgia State University, PO Box 3992, Atlanta, GA 30302-3992. Email: gturnbull@gsu.edu 
It would be relatively easy at this time for the 'experts' to write a prescription for housing older people which would take into account the changes in physical status, health, and social circumstances which accompany aging. To do so, however, without knowledge of the consumer's wants, would be short of folly.

--Donahue (1954, pp. 23-24)

\section{Introduction}

Long anticipated, the leading edge of the baby boomer generation is now entering its retirement years. How will this demographic tidal wave affect our communities? And, how will the growing numbers of elderly households, in turn, be affected by community responses to these changes?

This paper discusses some of the important issues that will confront community leaders as these demographic changes unfold in the coming decades. At root, community response to the challenges of an aging population is tied to the question of how to use our housing stock to meet the unique needs of older adults while, importantly, still accommodating the needs of the rest of the population. The difficulty our communities must confront is the reality that policy can open a range of lifestyle options for older adults, but the individuals will decide which path to take. While there is a large segment of the older adult population that is highly mobile, one of the realities that circumscribes policy is the desire of the majority (AARP, 2005) - perhaps two-thirds or more (Atlanta Regional Commission, 2007) - of older adults to remain in their current homes and communities for as long as possible. These facts shape the policy options and consequences for our communities.

As the Baby Boom generation (those born between 1946 and 1964) reaches retirement age after 2010, the percentage of the population that is elderly will increase rapidly. The oncoming wave of aging baby-boomers, as large as it is, is only a leading edge of even greater cohorts. By the year 2030 the number of people in the U.S. aged 55 or older is projected to grow by more than 51.3 million - 86.2 percent - and the 65 and older population will more than double - 104 percent - from 35 million in 2000 to 71.4 million in 2030. In 2030, almost 1 in 3 will be over 55; 1 in 5 will be over 65 . 
Table 1:

Projections of over 55 and over 65 US Population

$\begin{array}{rrrrr} & \begin{array}{c}\mathbf{5 5 +} \\ \text { Count } \\ \text { (millions) }\end{array} & \text { \% of total } & \begin{array}{c}\text { 65+ } \\ \text { Count } \\ \text { (millions) }\end{array} & \text { \% of total } \\ \mathbf{2 0 0 0} & 59.5 & 21.00 & 35.0 & 12.40 \\ \mathbf{2 0 1 0} & 76.4 & 24.75 & 40.2 & 13.00 \\ \mathbf{2 0 2 0} & 97.4 & 29.00 & 54.6 & 16.30 \\ \mathbf{2 0 3 0} & 110.8 & 30.50 & 71.4 & 19.60\end{array}$

$\begin{array}{lll}\text { Change 2000-2030 } & 51.3 & 36.4\end{array}$

Derived From: http://www.census.gov/ipc/www/usinterimpro/usproj2000-2050

Our communities will have to deal with the implications of rising proportions of aging adults. These baby-boomers differ from previous generations in terms of greater diversity in educational backgrounds and household composition. Metropolitan areas with a history of faster growth over the past several decades have already experienced significant immigration of baby-boomers who are now approaching 60 (Frey, 2007). These households are generally wealthier and have demonstrated that they are more willing to relocate than those remaining in slower growing metropolitan areas. The different socio-economic mix of aging populations in historically high growth areas also will place different demands on their local governments than in low growth areas. This emphasizes the importance of decisions made at the community level when dealing with the upcoming elderly housing issues; the variety of scenarios that will play out requires that solutions be targeted to meet local conditions. This paper discusses issues that policy makers and advocates of aging policy will have to address as a part of the necessary adjustment to the unavoidable demographic shift underway. The focus is on current housing and neighborhoods, not currently well suited to the needs of an aging population, and what communities can do to anticipate policy changes and open a range of lifestyle options for an elderly population most of whom are expected to age in place.

The discussion is organized as follows. Section 2 summarizes the population and housing demand changes that are likely to confront communities. Section 3 discusses the consequences of aging-in-place for both the aging households and their communities. 
Section 4 examines factors associated with the relatively small, but numerically important, segment of the aging population willing to relocate to satisfy their changing housing demands. The implications of the growing older adult population for community decision making is considered in Section 5. Section 6 summarizes a range of policy implications. Section 7 brings together the emerging elderly housing situation and ongoing affordable housing issues. Section 8 presents a summary and conclusions.

\section{The Challenge}

By 2030 we will see a near doubling of the absolute numbers of our elderly population. There are several ways that individual communities will experience increases in their aging adult populations. Out-migration of younger generations creates a rising proportion of left-behind elderly unwilling or unable to move. Among other things, this pattern may generate negative local fiscal impacts. On the other hand, in-migration of older adults into a community creates a rising population of elderly who are willing and able to move; among other things, there may be a positive local fiscal affect. The final possibility is the natural aging of an immobile population. Each source of aging population has different health and wealth consequences at the community level.

Regardless of the source of local growth in the older adult population, elderly housing problems arise from the fact that housing needs and demands change as a natural consequence of aging. This creates a persistent mismatch between the housing stock and households. With increasing elderly populations, the magnitude of the mismatch will grow. There are only two options to improve the match between housing stock and the needs of its occupants: either modify the characteristics of an aging household's home to better serve its evolving needs or move the aging household to a different home with characteristics that provide a better fit. Either strategy has its advantages and disadvantages.

In terms of housing the elderly, the policy question is the same today as in the past: How can the stock of housing be used to best meet the needs of older adults? The 
difference today is the sheer scale of the challenge; for the first time we have to answer this question for a growing rather than declining proportion of the population.

Most older adults in the U.S. live in suburbs, exurbs, smaller cities outside large metropolitan areas, and rural areas. These are also the places where the rates of growth in the old and young elderly populations are greatest. ${ }^{1}$ The vast majority of older adults, those 65 years old and older, want to remain in their current homes and communities (AARP, 2005). A survey in the Atlanta region found 64 percent of the older survey respondents wanted to stay in their existing home as long as possible. Attitudes like this among existing elderly populations clearly have policy implications for local suburban, exurban, small city and rural governments and communities.

What can we expect of the near elderly group - those likely to enter retirement in the next decade - as it ages? It is currently a largely suburban cohort. The question is whether they will remain in their current communities, move to other communities in or near the same urban area, or move out of state as they age. Will they have similar attitudes to the current $65+$ cohorts with similar policy implications for local governments? The answer is crucial to understanding the effects that this aging population will have on communities.

What do we know about the housing demand patterns of aging households? Our current dominant mind-set is that as people age they will move in ways consistent with the housing lifecycle; as they become "empty nesters" they will move and down-size their housing (Morrow-Jones et al., 2005). Specific influences on location choices are family composition, income, wealth, and physical abilities, mediated by their attachment for homes and neighborhoods formed through long term association.

A survey of Americans over 50 years old conducted by the AARP in 2004 reinforces a widely-held view that being closer to family and friends is an important factor driving elderly housing decisions (AARP, 2005). Yet, over time, family composition appears to have a declining influence on home ownership decisions,

\footnotetext{
${ }^{1}$ Households comprising individuals in the 55-64 age range are labeled "near elderly" or "pre-retirement." Households in the 65-74 age range are the "young elderly" while households with individuals over 75 years old are "old elderly." The age cutoffs are not entirely arbitrary; they approximate the traditional retirement benchmark and an age after which the proportion of adults with age-related health constraints rapidly rises, respectively. Collectively, we refer to these groups as "older adults."
} 
suggesting that the related factors associated with the life-cycle explanation of housing demand are becoming less important as well (Gyourko and Linneman, 1996, 1997). Nonetheless, life events associated with aging still affect the pattern of housing demands of older adults. Among the over-55 households who move, those who downsize appear to do so primarily because of poor health (Megbolugbe et al., 1997). This may mean either that these households are drawing upon their housing wealth to finance health care or that they are downsizing because they can no longer perform as much property maintenance.

Intergenerational wealth differences within families also affect the housing decisions of older adults, although sometimes in surprising ways. Megbolugbe et al. (1997) find that older households with adult children earning higher incomes tend to liquidate part of their housing equity by selling and buying a less expensive home while those with lower income children tend to invest in more housing by selling and buying a more expensive home when moving. These broad patterns emphasize that downsizing by older adults need not mean buying less expensive housing. Older households generally do not downsize to liquidate housing wealth to finance their retirement.

While several of these studies pertain to earlier cohorts (the near-elderly that are now elderly), the implications are still relevant to the current near-elderly and younger cohorts of the baby-boomers. The current near-elderly and younger household cohorts exhibit greater diversity in family structure and greater family dispersion than previous generations, features likely to reduce community attachment due to nearby family. They have fewer children and are more likely to be divorced one or more times (Frey, 2007). These differences suggest that these households might be more willing than the current elderly to move as their housing and health care needs change with age. We may not see as many of the next cohort moving into the 65+ age group committed to staying in the same house.

At the same time, however, a large segment of the aging baby boomer population is not accumulating sufficient savings beyond home equity (Gist et al., 2002). They are likely to become locked in to their current homes and will depend upon government benefits for retirement. Regardless of their earnings while working, many of these households will be low income elderly when retired. Their financial constraints may 
prevent them from moving to more elderly-friendly housing or communities even when willing to do so.

Home ownership rates are higher for adults over 50 than for younger households. There is also a tendency to shift from home ownership to renting when over-75 years old, an observation consistent with the notion that moves late in life are often precipitated by a change in health or death of a spouse. As explained below, homeownership factors importantly into low income households' decisions to age-in-place or move as they age.

Will there be a tendency for the current near-elderly cohort to be more or less tied to their existing homes than the current elderly cohorts? There are factors that seem to push and pull in both directions. Policy makers will be prudent to keep testing trends in this area.

\section{Aging-in-Place}

The majority of today's elderly want to age-in-place; ${ }^{2}$ they want to remain in their current home as long as possible. Household motives for moving vary by age group. Households more than fifty years old tend to move less often than do younger households, and when they do move, they move for different reasons. For example, households in the 50-64 range tend to move for better jobs or better housing while households over 75 years old move to obtain more affordable housing or for health reasons. Overall, the desire to be closer to family and friends rises in importance as the household ages (AARP, 2005).

\section{A. The Desire to Age-in-Place}

Aging-in-place means different things to different people, ranging from living in a particular home as long as possible or living in a series of homes in a particular community. It also refers to the process of moving in the pre-retirement period or

\footnotetext{
${ }^{2}$ For clarity, we define aging-in-place as remaining in the same home. We define aging-in-community to include aging-in-place as well as moving from one home to another in the same community. Aging-incommunity includes the process of moving into a structured community that offers the continuum of assistance that allows the household to remain there throughout its life.
} 
immediately at retirement into a structured multifamily community offering a continuum of assistance that increases with physical need (Prosper, 2004). Older Americans have a clear-cut definition of aging-in-place: Most older Americans want to stay in their current homes until forced to move by circumstances (AARP, 2005; Gelwicks and Newcomer, 1974; Golant, 1984). For example, in a 2004 survey of older adults, 66\% of 50-64 year olds, $83 \%$ of $65-74$ year olds, and $86 \%$ of those 75 and older expressed strong desires to stay in their current homes "as long as possible" (AARP, 2005). A 2007 survey by the Atlanta Regional Commission found that most older adults in the Atlanta region have been aging in place - living in the region an average of 37 years - and that 64 percent want to stay in their current home. If they do move, 52 percent want to stay in the metro region (Atlanta Regional Commission, 2007)

The attraction of aging-in-place is easy to understand. Long term familiarity with a community, established friendships, and life experiences associated with particular homes or neighborhoods create a place-specific amenity that, once left, is gone. Other factors affect the reluctance of older households to readily change homes or communities as their physical needs change. Some of these factors, discussed below, may become more important as additional cohorts of baby boomers approach elderly status.

Changes in retirement patterns can affect the willingness of older adults to move. Although the long-term pattern of earlier retirement is expected to continue (Gendell and Siegel, 1992), a subset of older households face stronger incentives to postpone formal retirement. Mandatory retirement in the U.S. was largely abolished in 1986 (Burtless and Quinn, 2000) and expected changes in Social Security over the next decades will provide incentives for later formal retirement. In addition, the incentives individuals face to extend their working lives are likely to grow because the dearth of younger workers replacing aging baby boomers increases the value of productive older workers to employers. Large debt burdens (Gist et al., 2002) may also force older people to continue working past retirement. Individuals are already increasingly using part time employment or second careers as bridges to complete retirement. Fifty-two percent of the 55+ respondents to the ARC survey plan to continue working in some manner after retiring from their present job (Atlanta Regional Commission, 2007). 
Any tendency toward later full retirement means that a segment of the older population will continue to be tied to locations near their primary employment. Policies that support aging-in-place will also be important to future cohorts of older adults whether or not they choose to extend their working lives.

In addition, some attempts to make elderly housing more affordable, like property tax assessment growth limits or homestead exemptions for the elderly, create lock-in effects for older homeowners by increasing the gross cost of moving to another home. These policies inadvertently increase the economic incentive to age-in-place.

The desire of most older Americans to age-in-place means that, regardless of whether or where they choose to live or recreate in second homes, the bulk of the current near-elderly population (aged 55-65) is likely to stay more or less where it is. This suggests that suburban and rural communities will have to make the greatest accommodations to deal with a large number of aging households. Given the stated preferences of most older adults to age-in-place, the question becomes: how does this desire affect communities and what must communities do to make this option work for their aging residents?

This desire to age-in-place also creates a mismatch between community features and elderly household lifestyles. Simply put, the community features that households find attractive in their earlier years will probably not meet their needs they age. Accessibility to employment sites, higher school quality, and newer housing are features valued by younger families drawn to suburban locations, but these are features that may not be as highly valued by older households. Suburban households over 50 tend to give their communities poor grades for a range of features like public transportation, proximity to drug and grocery stores, having a local hospital, and opportunities for volunteering and civic engagement (AARP, 2005). In the ARC survey, 57 percent of the $55+$ population expect to be driven around by others, reflecting poor public transportation in most parts of the region (Atlanta Regional Commission, 2007). Regardless of their desire to remain in their communities, these households recognize that their needs have changed and communities are no longer serving their needs as well as they did when they were younger. 


\section{B. Consequences for Individual Households.}

There are several dimensions to the housing unit-household mismatch from agingin-place. First, there is a quantity and quality mismatch. The housing unit may have more living space, larger yard, or larger garage and more outbuildings than the household will use at it ages. Second, there is a functional mismatch. Individuals who remain in their long-time homes must either adapt the structure to meet their changing physical needs as time passes or modify their lifestyle to accommodate the limitations imposed by the structure.

The size or quality mismatch need not be not problematic for the individual if it does not impose lifestyle constraints. A larger home or yard, however, saddles the household with higher property taxes, utility bills, and maintenance costs than smaller structures with smaller yards. The result ranges from an unnecessary drain on the household's budget to triggering an affordability crisis. When housing expenses crowd out spending on food, transportation, recreation, or even medical care, they adversely affect the household's quality of life. Short term relief can be obtained by decreasing property maintenance. This will either increase future maintenance obligations or degrade the property. It also creates a negative effect on the neighborhood that can become reinforcing when the neighborhood has a large density of older households facing similar maintenance issues; declining property values reduce the incentive for neighbors to maintain or upgrade their homes, leading to greater general decline. For the elderly, the loss of property value makes it financially more difficult to move to housing that better meets their needs, the result being that general neighborhood decline creates its own lock-in effect.

The functionality mismatch can also reduce quality of life. Remodeling to improve accessibility can be stressful and expensive. And many homes have features that cannot be adapted to serve the household's lifestyle. While some modifications reduce the routine maintenance burden, other features that cannot be changed force the household to increase maintenance spending, substituting paid for work for their own labor as their physical abilities to perform these tasks diminish. The result may be that the household modifies its lifestyle, leaving inaccessible living space unused. 
The surrounding neighborhood also matters. The risk of neighborhood decline, especially in low-income neighborhoods, threatens property values. Crime and transportation issues also affect quality of life. The ability to walk to local shopping and other services is important to households who curtail their driving as they age. ${ }^{3}$ Central city neighborhoods and low-density suburban subdivision developments each have different implications for the aging household in this regard.

Aging-in-place also keeps the household in a familiar social setting, increasing community engagement and social interaction. It appears that maintaining a sense of purpose and community engagement may have positive long-term effects on elderly health (Wong and Fry, 1998).

\section{Consequences for the Community}

Communities that successfully accommodate older homeowners will enjoy benefits. Elderly property owners are more engaged in the community than are renters, including being more involved in activities ranging from local governance to volunteering time to charities. The elderly are more physically active when living in a community in which they have been a long time, with positive consequences for their own quality of life and as well as the demands they place on social services (AARP, 2005).

There also are community costs that come with a population aging-in-community. The typical suburban land use pattern reflects long held zoning practices that separate residential and commercial uses and promote low residential densities. While separating residential and commercial uses does not affect the delivery of services to the elderly, low residential densities can increase the cost of providing elderly support services. Additionally separation of services and medical facilities from residential areas creates transportation dependencies for those who do not drive (ARC, 2005).

There are adverse selection effects associated with a population aging-incommunity. Most older adult interstate migrants are generally wealthier and healthier

\footnotetext{
${ }^{3}$ More than one in five (21 percent) Americans 65 and older do not drive. Neighborhood design that puts convenience shopping and other services within walking distance of elderly housing not only enhances independence, but promotes health. The CDC estimates that if 10 percent of adults began regular walking, heart disease costs would be reduced $\$ 5.6$ billion (Atlanta Regional Commission, 2005).
} 
than the average older adult (Coxe, 2003; Frey, 2007). This means that the population choosing to age-in-community will generally be less healthy and wealthy than average and will therefore place higher than average demands on local aging-related services.

Health care for aging adults tends toward ongoing care for chronic conditions, in contrast with the single-intervention model for acute care that is more applicable to younger individuals (Wiener and Tilly, 2002). Communities with larger populations of older adults aging-in-place will have to change their health service delivery systems to accommodate a new care model. As an initial step, communities are encouraged to emphasize preventive health care for the elderly, provide opportunities for physical activity including access to recreation facilities and activity encouraging neighborhood design, and community nutrition programs. In addition, with increasing longevity, there will be increasing need long-term care programs and facilities and affordable long-term health care insurance (Atlanta Regional Commission, 2007).

An increasing number of low-income elderly who no longer drive create special transportation issues. Suburban and urban bus and train systems are designed largely to serve commuters and not the irregular point-to-point transportation needs of the elderly. Low-density suburban and rural communities will confront added costs of providing transportation support to diffuse populations of needy elderly.

As discussed later, accommodating the housing demands of a diverse aging population calls for mixed density and mixed-use development, both of which represent significant departures from past planning paradigms. Surrounding neighborhoods often resist such development in suburban communities. Community leaders will have to balance the interests of the growing population of elderly with the interests of younger households who are trying to protect their lifestyles and home values.

\section{Mobile Older Households}

While a large majority of aging adults express their intent to stay in the same home throughout their lives, this still leaves a large number of aging households who want to and are willing to relocate. Many others may intend to remain in the same home but will 
have choices shaped by evolving financial and physical realities; some of these older adults will change their residence as they age in response to changing financial conditions, deteriorating health, or the desire to remain closer to (relocated) families or friends.

Attracting wealthier and healthier footloose older adults can be "gray gold" to a community. In-migration of older migrants who tend to be wealthier and healthier than the general older population can easily create a positive fiscal outcome. Not every community can attract these migrants; they move to amenities - attractive mountain and beach locations, for example. Wealthier healthy arrivals healthy yield the benefits of an older population discussed earlier coupled with the advantage that they likely will place fewer demands on local government services. They can more readily solve their housing and transportation problems through the private sector (assuming that the appropriate policies have been put into place to allow the development of their desired housing and care facilities). Life care and continuum of care communities reduce the need for public support as their health fails. They also bring with them purchasing power and generate local service employment to satisfy their housing, transportation, and health care demands, as well as their recreational and consumption spending.

The phenomenon of "boomerang retirees" creates additional net benefits to a locale that is attractive to footloose wealthy elderly households. Boomerang retirees are individuals who, after moving to an amenity-oriented location, later leave to return to their original community or move closer to family. Anecdotal evidence suggests that such moves are triggered by increasing disability or loss of a spouse. Nonetheless, boomerang households bring their desirable purchasing power to their adopted community and leave when their demand for support services rises.

On the other hand, there is a downside to policies designed to attract gray gold. To draw wealthier older adults through interstate migration, state and local governments must augment their natural amenities using policies that appeal to wealthier older migrants: innovative long-term care regulations to allow flexibility in elderly and health care, revised zoning and building codes to allow the development of communities with features desired by older adults, as well as modifying government provided recreational and transportation facilities to serve a wealthier elderly population. Oregon's experience 
with these policies illustrates that they attract wealthier healthy aging adults, but they also draw a significant proportion of less wealthy and less healthy elderly (Coxe, 2003). It is reasonable to expect individual communities that are attractive to gray gold to also attract needier elderly with the consequence of reducing net fiscal benefits to the overall community.

\section{Effects on Community Decision-Making}

Older households prefer a different range of services than their younger counter-parts. They are also widely recognized as a very politically active group with well organized lobbying organizations. What does the growth of this group imply for community governance?

While there will be reallocation of public sector resources away from other age groups toward the elderly, there are reasons to expect the local political process will not draw too many community resources away from existing services to support more agingrelated services. First, even though the percentage of population that is older than 65 is rising and will continue to do so for decades, it is not likely that this segment can reach a political tipping point in which the interests of younger generations can be totally ignored in the local political process. Second, even where such a tipping point is attained, aging households may still support services like education and infrastructure that benefit younger households in order to preserve the value of their largest single asset-their homes. Even when they do not value these services themselves, they have an incentive to support them if the services are valued by potential purchasers of their homes (Fischel, 2001). There is a large body of evidence that failure to provide services valued by younger households reduces property values and makes houses more difficult to sell (Zahirovic-Herbert and Turnbull, forthcoming). Finally, the elderly appear to have a sense of community that reinforces altruistic political behavior, as evidenced by their high degree of civic engagement when long term residents of a locale (AARP, 2005).

Some locales use circuit breakers, homestead exemptions or school tax abatements for the elderly to sever the tie between older households' property taxes and 
services provided to younger households. Not only are these policies popular with elderly households, they also insulate political support for those services. At the same time, however, they reduce the tax bases used to support the services, shifting a greater portion of the financing burden onto non-elderly households. It is possible that these types of policies can polarize younger and older residents as the elderly population withdraws a growing portion of the local tax base from supporting these services.

Finally, there will be two types of older adults in the community - those who aged-in-community and those who migrated to the locale as older adults. The former are likely to exhibit greater community attachment while latter are less likely to do so. Therefore, the benefits from a growing elderly population in terms of community engagement (e.g. volunteerism, active in community organizations) and local political action will depend upon the source of the growth in the elderly population.

In summary, it remains to be seen how local governments will respond with agecentered services for their constituents. There will be greater demand for aging-related services and the resources to provide additional services will have to come from somewhere. The willingness of various groups to bear the burden of financing these additional claims on community resources either through reductions in services important to them or through greater taxes and fees remains to be seen.

\section{Policy Implications}

Policy implications discussed here include policies involving both housing and neighborhoods. There are a number of factors that point to policies that incorporate newurbanist, livable-communities principles. There are also many factors that point to the notion that many, if not most, of the changing needs generated by the growing elderly population will be met by in the private market. An important role for state and local

governments will be facilitating appropriate market responses and containing market excesses and exploitation as well as finding way to support those whose needs are not met in the market. 
As noted earlier, the fundamental policy question today is the same as in the 1960s: how to make the housing stock and neighborhoods better serve aging households. What is different now is the matter of scale. Nonetheless, we expect that, if allowed, the market will respond to meet the demands of the wealthier elderly, in part by suitably modifying the formal retirement community concept. It does not take much imagination to foresee private developers offering mixed generation housing with a continuum of care option for older residents, a relatively minor variation on mixed use developments that are currently an integral part of the livable community model. The more intractable questions relate to the segments of the older adult population with modest wealth.

For the destitute and low income frail or disabled elderly, Olmstead v. L.C. et al. (1999) establishes an obligation for governments to provide assistance within a broad community environment. In terms of assistance to frail elderly, this judicial decision requires that housing be available in mixed-age settings where reasonable. The livable community environment embodies this notion. Other policies might not satisfy this requirement.

\section{A. Policies for Aging-in-Place}

Policies appropriate to individual homes include concerns of the costs of remodeling and maintenance, redesign for accessibility, and policies to permit mixed generation living arrangements.

Remodeling existing homes. Cost is the greatest barrier to remodeling existing homes to increase functionality for elderly occupants. Accessibility features may also violate local building codes and neighborhood or condominium covenants. Finally, unscrupulous contractors and inadequate inspections can impose unanticipated costs from settling legal disputes or additional repairs.

Local governments can use building code exemptions, contractor licensing and bonding requirements, and more stringent inspections to reduce some of these costs. There is a role for nonprofit community development organizations to coordinate the 
resources necessary to assist low income elderly households with subsidized financing or innovative equity sharing schemes.

Accessible design for new homes. Uniform or universal design policies designate and require specific features that increase home functionality for the elderly. In 1998 the United Kingdom adopted a building code requiring all new housing units to meet specific accessibility design criteria. The code requires: a level primary entry with no steps; an entry door wide enough to allow a wheelchair to pass through; similarly wide hallways; a full bathroom on entry level; raised outlets and lowered light switches; and a level or mildly sloped approach from the parking space to the entrance. One widely recognized problem with uniform design requirements like this is that they raise the cost of the entire housing stock, exacerbating housing affordability in many large urban areas. Further, it does not address existing housing stock. Accessibility features do not appeal to all home buyers, which increases the selling prices of the fixed supply of pre-code properties without the features. On the other hand, if the existing stock can be retrofitted to meet most of these criteria there is an argument against a broadly applied building code with these features, since it would be more efficient to subsidize such retrofitting for individual units occupied by elderly households than to impose these features on all. ${ }^{4}$

The question is whether builders will offer these features if not required by law? Builders will offer accessible houses if there is sufficient demand. The question may be one of reliable branding of the set of features. For example, consider the EasyLiving Home $^{(\mathrm{CM})}$ concept in Georgia. The EasyLiving Home $\mathrm{e}^{(\mathrm{CM})}$ is a voluntary certification program that encourages builders to incorporate simple accessibility features in single family and townhomes. These features include some of the accessibility code requirements enacted in the U.K. The relatively minor design changes needed to be certified as an EasyLiving Home ${ }^{(\mathrm{CM})}$ can be accomplished in new construction at about

\footnotetext{
${ }^{4}$ A related question for modifying existing houses is whether such modification is really efficient. In some cases, it is less costly to redesign the medical and assistance equipment required by aging adults. As an example, motorized scooters can replace wheelchairs inside houses. The scooters are designed to make the narrower halls, corners, etc., found in most houses easier to negotiate, and for many eliminate the need to make significant structural changes to accommodate the elderly resident.
} 
one tenth the cost of retrofitting existing homes. ${ }^{5}$ The certification program is relatively new in Georgia, with the first certified home built in April, 2002. It is already expanding into New Hampshire, Texas, and West Virginia.

This is one way that governmental and private nonprofit organizations can assist the private sector's efforts to meet the changing housing requirements of older adults. The program creates a recognizable branded set of features that reduce marketing costs for conforming houses. The branding rationale follows that used to implement similar marketing of energy efficient houses. Long term success depends in a large part whether new house buyers see the features as something that will enhance their own enjoyment of the property in the long run (if they are looking that far ahead) or enhance the value to potential future buyers thereby increasing its current market value.

Intergenerational group housing. Another policy option is to make the zoning or other regulatory changes necessary to allow elderly to take in unrelated individuals in mixgeneration living arrangements. This approach must first get past neighbors who are reluctant to have a "group home" or the elderly equivalent of halfway houses nearby. Surrounding residents often fear that group homes reduce property values. While they do reduce property values, the effect is localized (Colwell and Dehring, 2000).

Intergenerational housing can in principle meet some of the needs of aging adults. The idea is to use group homes to bring together unrelated individuals to live as a single social group emulating a family structure (Latimer, 1996; Kuehne, 1986). An elderly owner of an under-used property can then draw on the mixed age group of residents for daily help; younger residents benefit from being a member of a mutually supportive group as well as from inexpensive rent. The U.S. experience with intergenerational housing suggests that this is not going to be a popular way of making existing housing more functional for the elderly. The younger participants tended to treat the group arrangement as a way of obtaining cheap housing, regarding assigned duties and even "family" mealtimes as the cost of inexpensive accommodations. Far from stimulating a supportive intergenerational family environment, these arrangements run the risk of

\footnotetext{
${ }^{5}$ The cost estimates are based on information in www.concretechange.org/cost.htm and pertain to sites with topography amenable to the accessibility features. Not all sites are amenable.
} 
degenerating into a dysfunctional group, creating social stress that can end up reducing the quality of life of the elderly property owner (Folts and Muir, 2002).

\section{B. Policies for Aging-in-Community}

A livable community is structured to meet the changing demands of a household throughout all stages of its life. Livable communities have a range of housing options and accessible local services. Their configuration allows for personal independence and individual choice of community engagement and social interaction.

A community includes residents and businesses. Interactions within and among community stakeholders-residents, workers, and consumers-are affected by the physical structure of community. The stock of existing buildings, transportation infrastructure, and developable land suitable for accommodating different uses as well as the mix of neighborhoods together define the physical structure of a community. The physical layout of existing real estate and infrastructure affects accessibility and privacy within and between neighborhoods in the community. The layout affects how well the community serves the resident, working, and consumer populations, as well as property values (Matthews and Turnbull, 2007).

This community definition emphasizes that the growing elderly population is but one part of the community-albeit an increasingly important part for many. While the discussion here focuses on the older adult population and what its growth portends for communities, it is important to keep the broader view in mind. This implies that a livable community encompasses a variety of neighborhood configurations in close proximity.

Livable communities embody the notion of aging-in-community, mixed-age and mixed-use environments that open a range of lifestyle options for older adults. In terms of physical structures, it requires mixed housing density to allow households to move from low density to higher density aging-friendly neighborhoods without leaving the community. Accessibility is enhanced by exploiting new urbanist ideas of mixed-use walkable neighborhoods with nearby drug and grocery stores, restaurants, and other local services.

More problematic, the vision of livable communities includes a range of affordable housing arrangements. This is problematic because, if successful in solving 
the age-related housing issues within a mixed-age environment, livable communities will be highly desired by a wide range of households and therefore will exhibit higher property prices and rents. Government may be challenged, probably working with private developers, to spread costs in a way to aid to affordability for less wealthy elderly.

Livable communities engender greater variety of buildings, road patterns, and infrastructure than found in the low density suburban development where most urban area older adults currently live. This aspect of mixed use and mixed density development projects makes it easier to offer a wide variety of housing types within a relatively small geographic area. Aging households desiring or requiring a change in housing can retain important social networks (family, friends and neighbors) if age-appropriate housing is available within the community. Major changes can be introduced by designing new development or redevelopment projects around livable community concepts. Older inner suburban communities can be greatly affected by targeted in-fill and redevelopment in this direction as well.

This livable community concept is not amendable to rural environments.

Creating new neighborhoods. New development and redevelopment provide opportunities to incorporate livable community features. However, doing so requires significant changes to local zoning practices to allow mixed use developments that fully exploit existing public and mass transportation infrastructure. The requisite zoning changes are all the more difficult when subject to the pressures of opposing interest groups fully engaged in the local political process.

It is too easy to dismiss resistance by local property owners to new development patterns as uninformed NIMBYism. Increasingly, the burden will be on policy advocates to identify those options that enhance community living and those that do not. There is a legitimate basis for some NIMBYism, although maybe not as much as uninformed property owners often assume. Local policy makers must do a better job identifying and addressing problems like increased congestion that can be solved with adequate transportation infrastructure and therefore are not really concerned with the mixed-use development itself. Local policy makers must also do a better job identifying the effects 
of such development projects on surrounding property values in order to deal with concerns about the project itself from a basis of knowledge rather than casual empiricism. This requires a deeper understanding and appreciation for how urban real estate markets work.

There is evidence that developers are responding to this growing market. In early December, 2007, AARP and the National Association of Home Builders announced their first Livable Community Awards to "celebrate the ingenuity of the winners in meeting the growing need and demand for user-friendly homes and communities designed to meet the needs and abilities of all residents.” (Gosik, 2007, p. C1)

Retirement Communities. Retirement communities draw the more mobile amenityoriented older adults. These communities range from the formally organized development managed by an incorporated entity (e.g., management company or condominium association) to age-restricted neighborhoods with few age-related services. When surrounded by unrestricted neighborhoods, these developments allow aging households to remain in their community while moving into an environment that provides housing and support services to match their changing physical needs as they age. This type of infill development typically requires revised zoning or land use regulations to permit low-maintenance properties with smaller houses and yards or even mid- or highrise structures. The former (smaller houses) entail a relatively minor change in zoning focus, since community-wide density restrictions might be met with neighborhood parks or green areas, thereby preserving the character of the broader community. The latter (mid- and high-rise), however, run the risk of strong resistance from surrounding neighborhoods.

The resistance of neighboring households to infill retirement development may be greater when it follows the livable community format, and therefore exhibits features that significantly differ from the surrounding established community.

Naturally occurring retirement community (NORC). Unlike formal retirement communities, these communities are not planned at the outset, but arise naturally as a particular locale yields sufficiently dense clusters of elderly over time. A NORC is 
defined by the ages of the residents, whether they are the result of aging-in-place or migration. Their sizes range from a single multiple-unit building to an entire neighborhood. They arise when, for example, a condominium or housing cooperative sets up a nonprofit corporation to coordinate with service providers to serve their elderly residents.

The recognized model for naturally occurring retirement communities is Boston's Beacon Hill Village, self-organized community support group. The 400 members pay annual dues of $\$ 580$, or $\$ 780$ for a couple, and have access to carpenters, a chef, personal trainer, or home health aides. Support of this type relieves stress on aging people so they are not forced from their homes by dependence. Planners, senior housing experts, and social service providers, view this movement as having the potential of making "agingin-place” safe and affordable for the majority of elderly people. New NORCs are forming on Capita Hill, in Cambridge, New Canaan, Palo Alto, and Bronxville (Gross, 2007).

Recognizing that not all NORCs can be completely self-funding, but also recognizing the potential economic efficiencies, New York is setting up public support. The State of New York provides legal recognition and funds non-profit NORC organizations as a public-private partnership. In New York City, NORC organizations also obtain funding from charities and nonprofit housing organizations.

Retrofitting established neighborhoods. It may be necessary to change existing neighborhoods or parts of neighborhoods to incorporate some of the livable community features using small scale enclaves of mixed housing densities and mixed land uses. This, too, requires a new approach to zoning; many of the arguments applied to the development of new and infill neighborhoods apply here as well. The types of changes envisioned here will change the physical character of established neighborhoods. Very few residents who own property, however, find unanticipated changes in the character of their neighborhood palatable (Turnbull, 1994; Hughes and Turnbull, 1996). In most cases, inserting mixed uses or densities on individual parcels in established neighborhoods is likely to be politically infeasible. 
At a more modest level, mother-in-law apartments in otherwise single family houses open the opportunity for intergenerational housing on a family scale. This arrangement might also generate neighborhood resistance; when not occupied by elderly relatives, these apartments can end up occupied by unrelated renters. In covenantprotected neighborhoods in particular, residents can forestall such property modifications. In unprotected neighborhoods, zoning laws will have to be carefully sculpted to balance the potential rental externality effect on surrounding property values against the community gains from making intergenerational housing easier to obtain.

Back to the city? The neighborhoods of central cities and the older inner suburbs in metropolitan areas offer physical environments closer to the livable community concept than the low density pattern of suburban and exurban locales. In addition, redevelopment of newer housing is often at higher densities than the original land use, making it easier to provide mid-rise and high-rise housing without having to overcome the resistance of surrounding neighborhoods comprising single family housing.

The vision of "empty nesters and baby boomers ... trading their suburban tract homes for unconventional residences in the city” (ULI, 1999, p.7) makes good headlines, but is it relevant to the mobile near elderly and elderly? In almost every large city, downtown boosters point to the near elderly as the next engine of central city rebirth. Although this latest "back to the city" movement has been highly visible and much publicized in the popular press, most individuals over 50 years old wish to stay in their current homes as long as possible and most live outside core cities.

But what about the one third of the 50-64 year olds who are not strongly attached to their current homes? Given the size of the aging cohorts, this minority represents a significant number of potentially footloose households. If the experience of the previous generation is any indicator, it is not likely that most of these footloose aging households who have spent a large portion of their adult lives as owners of single family homes in low density suburban communities will find radical changes in their lifestyles appealing (Gelwicks and Newcomer, 1974; Golant, 1984)—not the least because moving from 
suburban and exurban communities to the central city entails moving from areas with lower housing costs to some of the most expensive locations in the metropolitan area. ${ }^{6}$

In addition, higher income households of all ages are more sensitive to disamenities like crime (Cullen and Levitt, 1989). This makes the central city and older inner suburbs less attractive unless their local governments can meet the public safety expectations of the suburban older population.

What about the likelihood of an influx of older households into refurbished inner suburb and central city single family housing neighborhoods? These neighborhoods are often more conducive to walking and better-served by public transportation and local commercial conveniences than low density suburban communities. Nonetheless, it is unlikely that these neighborhoods will attract a great influx of older residents. Older houses in historic neighborhoods in the central city or inner suburbs have the same or greater functional mismatch problem as newer suburban housing. In addition, these properties are more costly than newer housing located farther out because of high land values and property taxes as well as higher maintenance costs associated with older houses.

In summary, a large number of older households will probably move from their outer suburban and exurban communities to the older inner suburbs or the central city itself. They can be served by niche housing developments provided by the private market. Whatever their effect on the older urban communities in the interior of the metropolitan area, however, they will not approach the profound influence of the much larger cohorts remaining in their current communities farther out in the metropolitan area or in rural regions.

Financial products. New financial products may make it easier for elderly households to extract equity from their homes to modify or maintain their property or enhance their living standards. The demand for new financial products or flexible property ownership arrangements will grow with the size of the elderly population. Georgia's recent near

\footnotetext{
${ }^{6}$ Developers of mixed-use projects are familiar with "boomerang units.” These are units purchased by empty-nesters coming from low density suburban neighborhoods who, after living in their new condominiums for a short period, discover that the "excitement" and "hubbub" of the surrounding retail and restaurant establishments have become "noise" and "congested traffic." These units are back on the market in a year or less, often at reduced prices.
} 
disaster dealing with predatory mortgage financing legislation illustrates the importance of regulating new financial products and innovations in property law from an informed perspective. ${ }^{7}$ States will have to be careful to strike a balance between allowing innovations that will meet the special needs of elderly homeowners while protecting the elderly from being exploited to their disadvantage.

\section{Affordable Housing Issues}

Urban areas that are successfully generating higher paying jobs are growing urban areas. These are also places with large elderly and near elderly populations. Metropolitan areas pull in new residents as long as the quality of life and employment opportunities are better than in other areas that are not performing as well. The higher incomes and growing population increase property values and rents for new and existing houses and buildings. They also reduce the quantity and quality of low price and low rent housing available as more units are retired to be redeveloped as higher quality (and higher price) units and as the prices and rents of the remaining low quality units rise. Thus, lower income households find themselves either paying more for their housing or reducing their housing consumption by taking in additional roommates.

The problem of affordable housing for low income households in a growing urban area is reflected in the larger proportion of their incomes needed to stay in their homes or apartments. Affordable housing affects both the young and old. The elderly, however, face additional constraints that the young do not, making their housing affordability problem more difficult to solve.

The affordability problem for the general population tends to be concentrated in central cities and older inner suburbs that contain a large part of the housing stock serving low-income consumers. Much of the low-income housing is older, which means that it is less functional for elderly residents as well as more difficult and costly to maintain. The result is that elderly households owning or renting older low-income housing are caught

\footnotetext{
${ }^{7}$ In 2004, the Georgia legislature tried to reign in "predatory lending” by making all entities in the mortgage and derivative asset chain of ownership liable for acts undertaken at origination. The legislation would have effectively prevented all mortgages originated in Georgia from participating in secondary investment markets. The legislation was quickly rescinded.
} 
between rising rents or property values (hence rising property taxes) and maintenance costs that keep rising as the housing unit ages.

While most of the homeowners over 50 years old have no mortgage or have small mortgage balances, more than one fifth still pay over 30 percent of their incomes for housing costs like insurance, property taxes, utilities, and maintenance (Joint Center for Housing, 2004; AARP, 2005). The affordability problem is acute for low-income nearelderly and elderly households but it is also significant for those with most of their wealth in the form of home equity. Low-income older households in the older inner suburbs and central city can find their situations exacerbated by rising property taxes and maintenance costs. At the same time, the redevelopment of neighborhoods containing low income housing with larger homes or multi-unit buildings changes the neighborhood character, possibly reducing the support network of friends and family as they move out, reducing neighborhood attachment and quality of life for the elderly who remain aging-in-place.

The same type of low-income housing development subsidies and housing certificates or vouchers that apply to younger households will assist elderly renters as well. For owners, however, the two major existing affordability policies tend to be geared toward younger households: financial programs targeting first-time buyers and mortgage deductibility for income taxes (which only has value if the owner has a mortgage and sufficient income to be taxed). There are other programs that help upgrade property to improve energy efficiency as well as direct energy assistance. Similar programs subsidize repairs and maintenance for elderly low income homeowners. For older inner suburban and central city communities, the danger is that the rising demand for these programs may outstrip the resources of organizations currently involved in them.

Finally, we find ourselves back at a point made earlier, that advocates for elderly housing and policy makers must become more knowledgeable about how real estate markets work, if only to avoid unintended secondary effects of well-meant policies. For example, growth control policies enacted to regulate sprawl increase the prices of new and existing housing units, further reducing the availability of less expensive housing serving the low income population of the urban area (Turnbull, 2004; Downs, 2004). Communities need to exercise care that policies undertaken to meet the challenges of the 
elderly do not unduly exacerbate the affordability problem confronting many young and elderly households.

\section{Conclusion}

The demographic tidal wave known as the baby boomer generation is now entering its retirement years. Our existing housing stock, transportation systems, and health care delivery systems are not set up to accommodate the changing needs of this group as it ages. Where they will live and how they will live are questions tied to how they will satisfy their primary housing concerns. This paper discussed why the current homes and neighborhoods of aging adults may serve them poorly as they age. The focus was on what communities can do to anticipate policy changes that will need to be made.

The perspective offered here emphasizes that the best communities can do is to open a range of lifestyle options for older adults. The individuals themselves will decide which options best suit their needs. While there will be a large number of mobile elderly, an overwhelming majority of near-elderly and elderly households wish to age-in-place. Relevant policies must face this fact.

Therefore, suburban, exurban, and rural communities will remain home to most of its aging population. Unfortunately, the housing stock and neighborhood configurations in these locales are not conducive to a growing elderly population aging-in-place. This paper discussed issues communities will have to address if they wish to successfully remake themselves into livable communities that will do a better job meeting the evolving needs of this population. The question is how to make the transition to communities with mixed densities and uses, that are pedestrian-friendly, and have transportation systems that support a wider range of point-to-point travel by the elderly, while still meeting the needs of younger households.

Many issues are likely to be addressed by market responses of builders and voluntary associations of community residents. An important part of state and local government response will be to work with these emerging trends and communities with new zoning and building codes and social network support. 


\section{REFERENCES}

AARP, Beyond 50.05: A Report to the Nation on Livable Communities: Creating Environments for Successful Aging, www.aarp.org, 2005.

ARC, The Aging of Atlanta: Are We Ready? Atlanta: Atlanta Regional Commission, 2005

Burtless, G., and J. F. Quinn, "Retirement Trends and Policies to Encourage Work Among Older Americans,” manuscript, Economics Department, Boston College, 2000. http://eScholarship.bc.edu/econ_papers/175

Colwell, P. F., and C. Dehring, "The Effects of Group Homes on Neighborhood Property Values,” Land Economics, 2000, 76: 615-637.

Coxe, L. M., "Public Policy Implications of Elderly Interstate Migration to Oregon, 1985-1990,” Journal of Aging \& Social Policy, 2003, 15: 79-94.

Cullen, J. B., and S. D. Levitt, "Crime, Urban Flight, and the Consequences for Cities," Review of Economics and Statistics, 1989, 81: 159-169.

Donahue, W., "Where and How Older People Wish to Live,” in W. Donahue, ed., Housing the Aging, Ann Arbor: University of Michigan Press, 1954.

Downs, A., Growth Management and Affordable Housing: Do They Conflict?, Washington, DC: Brookings Institute. Press, 2004.

Fischel, W., The Homevoter Hypothesis, Cambridge, MA: Harvard University Press, 2001.

Folts, W. E., and G. F. Streib, “Leisure Oriented Retirement Communities,” in W. E. Folts and D. E. Yeatts, eds., Housing and the Aging Population: Options for the New Century, New York: Garland Press, 1994.

Folts, W. E., and K. B. Muir, "Housing for Older Adults: New Lessons from the Past," Research on Aging, 2002, 24: 10-28.

Frey, W. H., Mapping the Growth of Older America, Washington, DC: Brookings Institution, 2007.

Gelwicks, L. E., and R. J. Newcomer, Planning Housing Environments for the Elderly, Washington, DC: National Council on Aging, 1974.

Gendell, M., and J. S. Siegel, “Trends in Retirement Age by Sex, 1950-2005,” Monthly Labor Review, July 1992, 22-29. 
Gist, J and C. Figueiredo, Deeper in Debt: Trends Among Midlife and Older Americans. Washington, D.C.: AARP Public Policy Institute, 2002

Golant, S. M., A Place to Grow Old: The Meaning of Environment in Old Age, New York: Columbia University Press, 1984.

Golant, S. M., Housing America’s Elderly: Many Possibilities/Few Choices, Newbury Park, CA: Sage, 1992.

Gosik, Ashley, “Making Older Folks Feel at Home”, Atlanta Journal-Constitution, December 15, 2007, C1

Gross, J. “Elderly Organize to Meet Problems of Aging,” New York Times, August 13, 2007

Gyourko, J. and Linneman, P. “Analysis of the Changing Influences on Tranditional Housholds’ Ownership Patterns,” Journal of Urban Economics, 1996, 39: 318-341.

Gyourko, J. and Linneman, P. "The Changing Influences of Education, Income, Family Structure and Race on Homeownership by Age over Time,” Journal of Housing Research, 1997, 39: 318-341.

Hughes, W. T., Jr., and G. K. Turnbull, "Uncertain Neighborhood Effects and Restrictive Covenants,” Journal of Urban Economics, 1996, 39: 160-172.

Joint Center for Housing Studies, State of the Nations Housing: 2004, Cambridge, MA: Harvard University, 2004.

Kuehne, V. S., "Evaluate Your Intergenerational Program: Four Recommendations for Human Services Practitioners,” Southwest Journal on Aging, 1996, 12: 27-32.

Latimer, D. J., “The Intergenerational Movement,” Southwest Journal on Aging, 1996, 12: $1-3$.

Matthews, J.W., and G. K. Turnbull, "Neighborhood Street Layout and Property Value: The Interaction of Accessibility and Land Use Mix," Journal of Real Estate Finance and Economics, 2007, 35: 111-141.

Megbolugbe, I. F., J. Sa-Aadu, and J. D. Shilling, “Oh, Yes, the Elderly will Reduce Housing Equity under the Right Circumstances,” Journal of Housing Research, 1997, 8: 53-74.

Morrow-Jones, H. A. and M. V. Wenning, "The Housing Ladder, the Housing LifeCycle and the Housing Life-course: Upward and Downward Movement among Repeat 
Home-buyers in a US Metropolitan Housing Market,” Urban Studies, 2005, 42: 17391754.

Olmstead v. L.C. et al. 527 US 581 (1999).

Prosper, V. “Aging in Place in Multifamily Housing,” Cityscape: A Journal of Policy Development and Research, 2004, 7: 81-106.

Turnbull, G. K., "Location and Housing Demand with Endogenous Consumption Risk,” Regional Science and Urban Economics, 1994, 24: 543-563.

Turnbull, G. K., "Urban Growth Controls: Transitional Dynamics of Development Fees and Growth Boundaries,” Journal of Urban Economics, 2004, 55: 215-237.

ULI, Housing in the $21^{\text {st }}$ Century, Washington, DC: Urban Land Institute, 1999.

Wang, T. P., and P. S. Fry, The Human Quest for Meaning: A Handbook of Psychological Research and Clinical Applications, Mahwah, NJ: Lawrence Erlbauer, 1998.

Weiner, J. M, and J. Tilly, "Population Aging in the United States of America: Implications for Public Programs,” International Journal of Epidemiology, 2002, 31: 776-781.

Zahirovic-Herbert, V., and G. K. Turnbull, "School Quality, House Prices and Liquidity,” Journal of Real Estate Finance and Economics, forthcoming. http://aysps.gsu.edu/urbanregional/workingpapers/ 